\title{
Effects of tripterygium glycosides on restenosis following endovascular treatment
}

\author{
BING HAN, CHANG-QING GE, HONG-GUANG ZHANG, CHEN-GUANG ZHOU, \\ GUO-HUI JI, ZHENG YANG and LIANG ZHANG
}

Department of Vascular Surgery, The Second Hospital of Baoding, Baoding, Hebei 071051, P.R. China

Received March 10, 2015; Accepted January 12, 2016

DOI: $10.3892 / \mathrm{mmr} .2016 .5149$

\begin{abstract}
The mechanism and associated factors of restenosis following intravascular stent implantation remain to be elucidated. The present two-part experimental and clinical study aimed to investigate the effects of tripterygium glycosides on in-stent restenosis subsequent to intra-arterial therapy. Following endovascular stent implantation in rabbit iliac arteries, post-stent outcomes were evaluated in cyclosporine groups, low-dose and high-dose tripterygium glycosides groups and controls. Post-operative angiography indicated that vessel diameters were similar between groups; however, at 28 days after receiving the therapeutic agents, vessels of the cyclosporine and tripterygium glycosides groups were significantly larger than those of the controls. Furthermore, three groups of patients had comparable baseline levels of interleukin (IL)-10, IL-18 and C-reactive protein, and intima-media thickness. However, 1 month after stent implantation, levels of IL-10 and IL-18 were markedly reduced in the high- and low-dose tripterygium glycosides groups compared with controls. At 6 months after surgery, the stent patency rate in patients with bare stents was significantly lower than in patients receiving tripterygium glycosides $(\mathrm{P} \leq 0.009)$. In addition, the ankle-brachial index was also higher than in those without tripterygium glycosides $(\mathrm{P}<0.001)$. Results of the experimental and clinical studies suggest that tripterygium glycosides may inhibit and possibly aid in the prevention of in-stent restenosis formation following endovascular treatment of lower-extremity artery disease.
\end{abstract}

\section{Introduction}

Endovascular treatment via stent implantation or percutaneous transluminal coronary angioplasty (PTCA) is the preferred method for lower extremity arterial occlusive diseases $(1,2)$.

Correspondence to: Dr Bing Han, Department of Vascular Surgery, The Second Hospital of Baoding, 338 Dongfengxi Road, Baoding, Hebei 071051, P.R. China

E-mail: binghan1023@yeah.net

Key words: lower extremity artery disease, proliferation, restenosis, stent, tripterygium glycosides, vascular smooth muscle cell
PTCA has been the predominant method of coronary revascularization; however, the incidence of restenosis is $30-50 \%$, which limits its use and increases the use of drug-eluting stents (3). Results from treating superficial femoral artery disease by implantation of nitinol stents were superior to those treated with balloon angioplasty with optional secondary stenting, with 6-month restenosis in $24 \%$ of the patients with stents and in $43 \%$ of patients receiving angioplasty (2). At 12 months, the patency rates are 37 and $63 \%$, respectively, with $32 \%$ of angioplasty patients receiving secondary stenting (4). Asymptomatic in-stent restenosis (ISR) and neointimal proliferation are observed in patients with stent implantation as early as one year subsequent to treatment (1). ISR appears to be the result of a number of factors and investigators have presented multiple hypotheses, including early-stage vascular recoil, platelet aggregation and thrombus formation, infiltration of local inflammatory cells ( $\mathrm{T}$ lymphocytes, neutrophils and monocyte-macrophage cells) into the damaged blood vessels, neointimal hyperplasia and extracellular matrix formation, and remodeling of blood vessel walls $(3,5-7)$. However, a definite cause-effect association remains to be determined. Although drug-eluting stents are used consistently to effectively reduce ISR $(8,9)$, restenosis remains a critical clinical issue for vascular surgeons.

The Chinese herb, Tripterygium wilfordii Hook F (TWHF), has long been reported to exhibit anti-inflammatory and immunosuppressive effects $(10,11)$, which are largely attributed to the diterpenoid triepoxides, triptolide and tripdiolide (the predominant components of the herb) (12). The purified extract triptolide has been widely used in Chinese traditional medicine to treat inflammatory and autoimmune diseases, including rheumatoid arthritis, lupus erythematosis, nephritis and asthma. Triptolide combined with cyclosporin A (CsA) induced immune tolerance in a rat renal allograft rejection model (13). Triptolide extracted from TWHF has also been demonstrated to exhibit antiproliferative and pro-apoptotic functions in a number of tumor cell lines $(14,15)$. Recently, it was investigated for its effects on ISR inhibition of rat vascular smooth muscle cell (VSMC) proliferation and cell cycle progression, demonstrating an inhibitory effect on the VSMC cell cycle, inactivation of the mitogen-activated protein kinase signaling pathway and modulation of cell cycle proteins, cyclin-dependent kinase inhibitor 1 (p2 $1^{\text {cipl} 1)}$ and retinoblastoma protein (16). It was also demonstrated 
that triptolide-eluting stents attenuated neo-intimal formation following stent implantation in rabbit blood vessels (16).

Tripterygium glycosides that are used commercially for their anti-inflammatory and immunosuppressive effects are extracted from TWHF by column chromatography. Although its use is considered effective in the treatment of inflammatory and autoimmune diseases, it is also associated with toxic effects to the liver and kidneys. In a recent study, the cytotoxic effects and anti-inflammatory activity of the three components of tripterygium glycosides were evaluated in an effort to reduce toxicity (17). Toxicity was thus reduced by changing the extraction method from column chromatography to sodium carbonate extraction, which removed the acidic compounds, and enriched the epoxyditerpenoids and alkaloids in the resulting extract. Animal experiments have demonstrated that the therapeutic index of the extract on rat tissue (murine macrophage and mesangial cells) was markedly higher than that of tripterygium glycosides, and the cytotoxicity in human liver cells was notably lower (17). The toxic effects were thereby reduced and the novel tripterygium glycosides preparation demonstrated effective biological activity and safety in human patients.

VSMC proliferation is a key factor in the mechanism of restenosis; thus, inhibiting this process is hypothesized to exert a beneficial therapeutic effect on ISR. The present study hypothesized that if tripterygium glycosides inhibit cell proliferation, cell cycle progression and protein expression in an animal model of stent implantation, differences may also be observed in outcomes between patients receiving tripterygium glycosides and bare-stents following endovascular treatment of lower-extremity artery disease. With the exception of the recent study by Tao et al (16), no published studies have focused on the effect of tripterygium glycosides on restenosis. Thus, the present two-part experimental and clinical study aimed to investigate the effects of oral administration of tripterygium glycosides on ISR.

\section{Materials and methods}

Two-part study. The current two-part prospective study included a basic experimental study and a follow-up clinical study. The experimental study was performed between January 2010 and March 2010 and the clinical study was conducted between May 2010 and January 2014 at the Department of Vascular Surgery, The Second Hospital of Baoding City (Baoding, China). The Internal Review Board and the Institutional Animal Care and Use Committee of the hospital reviewed and approved the study protocol. Animals were cared for according to the Regulations for the Administration of Affairs Concerning Experimental Animals (http://old.biovip.com/content/20050417/11036.htm). All human subjects in the clinical study provided signed informed consent to participate.

\section{Experimental study}

Experimental procedure. Twenty-four healthy male New Zealand white rabbits (age, 2-3 months; weight, $2.0 \pm 0.30 \mathrm{~kg}$ ) were purchased from the Experimental Animal Center of Hebei Medical University (Shijiazhuang, China). The rabbits were maintained at $20-23^{\circ} \mathrm{C}$, with $40-60 \%$ humidity and a $12-\mathrm{h}$ light/dark cycle. They were fed a normal diet for one week and then received implantation of an endovascular stent (ev3 bare-metal coronary artery stents with diameter and lengths of 3.0 and 10-18 mm, respectively; Lepu Medical Technology Co., Ltd., Beijing, China). Following successful implantation, the rabbits were randomly divided into four groups: Bare stent group; CsA (Novartis International AG, Basel, Switzerland) group, $0.5 \mathrm{mg} / \mathrm{kg}$ tripterygium glycosides (Shanghai Fudan Forward S\&T Co., Ltd., Shanghai, China) group; and $1 \mathrm{mg} / \mathrm{kg}$ tripterygium glycosides group. All agents were administered 1 day after balloon angioplasty injury via intramuscular injection to the iliac arteries and were continued for 28 days. All rabbits were sacrificed at day 29 by anesthesia with $10 \%$ potassium chloride (injected into rabbit ear vein).

Therapeutic agents. Tripterygium glycosides in tablet form were isolated and purified from tripterygium, as the components triptolide and tripdiolide have been indicated for use as anti-inflammatory and immunosuppressive compounds, as previously described (10). Following endovascular stent implantation, $7.14 \mathrm{mg} / \mathrm{kg} /$ day CsA was administered by intramuscular injection for the first 5 days, $1.02 \mathrm{mg} / \mathrm{kg} /$ day CsA was administered from days 6-14, and $0.678 \mathrm{mg} / \mathrm{kg} /$ day CsA was administered from days 15-28. Animals were administered $3.0 \mathrm{~g}$ finely ground tripterygium glycosides powder mixed evenly with $0.5 \%$ sodium carboxymethyl cellulose (Sigma-Aldrich), and suspended in $100 \mathrm{ml}$ solution and 3.0 and $1.5 \%$ solutions were prepared in turn. Dosage was determined according to the equivalent dosage for human beings; low and high doses of the therapeutic agents for the rabbits were 3 times $(1.5 \mathrm{mg} / \mathrm{kg} /$ day) and 6 times $(3.0 \mathrm{mg} / \mathrm{kg} /$ day $)$ the daily doses for human beings due to their faster metabolic rate, and prepared for intragastric administration.

Rabbit iliac artery angiography. A Siemens angiography system was applied (Siemens AG, Munich, Germany), measuring intima-media thickness at a frequency range of 4-9 Hz and observing for morphologic deformities, including plaque, stenosis and occlusion. Inner stenosis was calculated using the Siemens angiography system. Each rabbit was fixed and the left femoral artery was exposed and isolated. Injection of 5-10 ml iohexol (contrast agent; Sigma-Aldrich) from a $100 \mathrm{ml}$ solution containing $30 \mathrm{~g}$ iodine was administered to display the left iliac artery and the right iliac artery containing the endovascular stent and the images were captured and saved using the Siemens angiography system.

Material collection. Rabbits were sacrificed at the end of the experiment (day 29) following anesthesia. The rabbit iliac artery containing the stent was aseptically removed. The artery included adjacent proximal and distal vessel segments $5 \mathrm{~mm}$ in length, which were divided into two parts. One part was fixed with $4 \%$ paraformaldehyde (Sigma-Aldrich) for hematoxylin and eosin staining (Sigma-Aldrich) and immunohistochemical staining. The second part was fixed with $3 \%$ glutaraldehyde (Sigma-Aldrich) for examination with an S-3400 N scanning electron microscope (Hitachi, Tokyo, Japan).

Immunohistochemistry (IHC) of proliferating cell nuclear antigen (PCNA), vascular endothelial growth factor (VEGF), cyclin-dependent kinase 2 (CDK2) and $p 21^{C i p l}$. The rabbit iliac artery tissue sections were stained using Histostain-Plus kits (Zhongshan Biological Products Co., Ltd., Beijing, China) according to the manufacturer's protocols. The sections were 
subsequently incubated with primary antibody at $4^{\circ} \mathrm{C}$ overnight, and then with secondary antibody at room temperature for $15 \mathrm{~min}$. Primary antibodies included: $0.1 \mathrm{ml}(100 \mu \mathrm{g} / \mathrm{ml})$ of monoclonal mouse anti-PCNA $(1: 5,000$; Wuhan Boster Biological Technology, Inc., Wuhan, China; cat. no. 610664), $0.1 \mathrm{ml}(100 \mu \mathrm{g} / \mathrm{ml})$ of polyclonal rabbit anti-VEGF (1:200; Abcam, Cambridge, MA, USA; cat. no. ab46160), $0.1 \mathrm{ml}$ $(100 \mu \mathrm{g} / \mathrm{ml})$ of polyclonal rabbit anti-cyclin-dependent kinase 2 (CDK2; 1:200; Wuhan Boster Biological Technology, Inc.; cat. no. 8233343), and $0.1 \mathrm{ml}(100 \mu \mathrm{g} / \mathrm{ml})$ of monoclonal mouse anti-cell-cycle regulatory protein (p21 ${ }^{\mathrm{Cip} 1} ; 1: 250$; Wuhan Boster Biological Technology, Inc.; cat. no. 554262). The secondary antibodies included biotin-labeled goat anti-rabbit IgG (SP-9001) and biotin-labeled goat anti-mouse IgG (SP-9002). Following washing with phosphate-buffered saline, the sections were incubated with horseradish peroxidase-labeled streptavidin at room temperature for $15 \mathrm{~min}$. 3,3-Diaminobenzidine (Sigma-Aldrich) was applied followed by hematoxylin counterstaining. Sections were examined with a BX60 microscope (Olympus Corporation, Tokyo, Japan).

\section{Clinical study: Patients and methods}

Study design. This was a prospective case-control clinical study evaluating the effects of tripterygium glycosides on restenosis in patients undergoing balloon angioplasty and stent implantation. As tripterygium glycosides have been used in clinical practice in China prior to the present study, it was not registered as a clinical trial. This was in accordance with a previous systematic review of Chinese herbal medicines used for preventing in-stent coronary stenosis following percutaneous coronary intervention (18).

Subjects. A total of 120 patients who had undergone treatment for cardiovascular disease were included. Diagnoses were made according to guidelines of the Chinese Association of Integrative Medicine (19). Inclusion criteria were: i) Symptoms including leg coldness, numbness and pain, and/or intermittent claudication or physical signs, such as low lower-extremity skin temperature, decrease or absence of dorsalis pedis artery pulse; ii) presence of arterial plaque formation or occlusion in the lower extremity proven by arterial Doppler exam of the lower extremities; iii) presence of stenosis or occlusion in the superficial femoral artery confirmed by angiography; and iv) patients who were in the second stage (dystrophy period) or third stage (necrosis stage) of ISR. Based on the random number table, patients were divided into a control group of 40 patients (42 limbs), a low-dose tripterygium glycosides group of 40 patients (45 limbs) and a high-dose tripterygium glycosides group of 40 patients (43 limbs) at a ratio of 1:1:1. Patients with the following were excluded from the study: i) Associated severe renal dysfunction (indicated by creatinine clearance rate $<30 \mathrm{ml} / \mathrm{min}$ ), liver dysfunction (Child-Pugh classification grade B or C), heart failure (New York Heart Association functional classification grade III or IV); ii) a variety of acute complications of diabetes or stress states, including serious diseases and critical conditions; iii) associated malignant diseases and active bleeding disorders; iv) taking therapeutic agents affecting evaluation of the present therapeutic agent efficacy, including other vasodilators and therapeutic agents affecting microcirculation (including pentoxifylline, hormones, clofibrate, pyridolcarbates and nicotinic acid); v) occlusive thrombotic vasculitis and aorto-arteritis; vi) adverse reactions, such as a marked decrease in the number of white blood cells or liver and kidney damage during tripterygium glycosides treatment, which required therapeutic agent withdrawal, and who failed to recover after two weeks.

Treatment protocol. All 120 patients underwent endovascular treatment (balloon angioplasty or stent implantation). Bare metal stents (ev3 bare-metal stent) were implanted in the coronary artery of all patients. The range of endovascular stent diameters was $6.0-7.0 \mathrm{~mm}$, and the range of endovascular stent length was $6-12 \mathrm{~mm}$. Subcutaneous injection of low molecular weight heparin $(5,000 \mathrm{U} / 8 \mathrm{~h})$ was conducted for 5 days. Clopidogrel bisulfate (75 mg/day; Sigma-Aldrich) was administered for 3 months. The low-dose group received $0.5 \mathrm{mg} / \mathrm{kg} /$ day tripterygium glycosides in tablet form administered orally twice a day for 60 days (with routine blood tests performed once every two weeks and liver and kidney function tests once every month). The high-dose group received $1 \mathrm{mg} / \mathrm{kg} /$ day tripterygium glycosides in tablet form administered orally twice a day for 60 days (with routine blood tests performed once every two weeks and liver and kidney function tests once every month).

Main outcome measures. Prior to administration of therapeutic agents and at 4 and 12 weeks following treatment, fasting venous blood samples were drawn in the morning. Interleukin (IL)-10, IL-18 and C-reactive protein (CRP) levels were measured by enzyme-linked immunosorbent assay (R\&D Systems, Inc., Minneapolis, MN, USA), and the intima-media thickness and patency rate of the lower extremity arteries were detected by Doppler ultrasound (ACUSON S2000, Siemens AG) and built-in software.

Statistical analysis. Differences in vessel diameter (VD), post-operative diameter, measurements of lumen/neointimal (NI)/medial (M) area, ratio of NI-to-M, protein expression levels amongst the four groups of rabbits, as well as the baseline characteristics, protein expression levels, number of stents without marked intimal hyperplasia and ankle-brachial index (ABI) amongst the 3 groups of patients were compared using Fisher's exact or $\chi^{2}$ tests for categorical variables and one-way analysis of variance (ANOVA) for continuous variables. Following the ANOVA, post hoc analysis was conducted with multiple comparisons, including the significance of pair-wise differences tested using Tukey's test for balanced design with equal variance, Bonferroni's correction for unbalanced design with equal variance, or Dunnet's T3 test for unequal variance amongst groups. Tukey's test and Dunnet's T3 test consider familywise error. Group effect, time effect and the interaction between these two parameters were examined by generalized estimation equation. All tests were 2 -sided and $\mathrm{P}<0.05$ was considered to indicate a statistically significant difference. All analyses were conducted using SPSS software package version 15.0 (SPSS, Inc., Chicago, IL, USA).

\section{Results}

High-dose tripterygium glycosides improve the post-operative vessel diameter (POVD) and ratio of NI to $M$. Following administration of the therapeutic agents to the 4 groups of rabbits as described above, angiography of the iliac artery stenosis was conducted at 28 days (Fig. 1). The angiography prior to 
Table I. Iliac arteriostenosis in 24 rabbits.

\begin{tabular}{|c|c|c|c|c|c|}
\hline Parameter & $\begin{array}{l}\text { Vehicle control } \\
\qquad(\mathrm{n}=6)\end{array}$ & $\begin{array}{l}\text { CsA } \\
(n=6)\end{array}$ & $\begin{array}{l}\text { Low-dose tripterygium } \\
\text { glycosides }(\mathrm{n}=6)\end{array}$ & $\begin{array}{l}\text { High-dose tripterygium } \\
\text { glycosides }(\mathrm{n}=6)\end{array}$ & P-value \\
\hline $\mathrm{VD}(\mathrm{mm})$ & $2.46 \pm 0.03$ & $2.48 \pm 0.03$ & $2.47 \pm 0.05$ & $2.48 \pm 0.02$ & 0.632 \\
\hline POVD (mm) & $2.87 \pm 0.05$ & $2.90 \pm 0.03$ & $2.88 \pm 0.03$ & $2.89 \pm 0.03$ & 0.555 \\
\hline POVD/VD & $1.17 \pm 0.01$ & $1.17 \pm 0.02$ & $1.17 \pm 0.02$ & $1.17 \pm 0.02$ & 0.996 \\
\hline POVD at D28 $(\mathrm{mm})$ & $1.21 \pm 0.03$ & $2.18 \pm 0.04^{\mathrm{a}}$ & $1.97 \pm 0.03^{\mathrm{a}, \mathrm{b}}$ & $2.21 \pm 0.03^{\mathrm{a}, \mathrm{c}}$ & $<0.001^{\text {d }}$ \\
\hline Loss in POVD at D28 (mm) & $1.66 \pm 0.03$ & $0.72 \pm 0.05^{\mathrm{a}}$ & $0.88 \pm 0.10^{\mathrm{a}, \mathrm{b}}$ & $0.68 \pm 0.05^{\mathrm{a}, \mathrm{c}}$ & $<0.001^{\mathrm{d}}$ \\
\hline $\begin{array}{l}\text { Percentage change of POVD } \\
\text { at day } 28(\%)\end{array}$ & $57.77 \pm 0.79$ & $24.83 \pm 1.61^{\mathrm{a}}$ & $30.42 \pm 3.28^{\mathrm{a}, \mathrm{b}}$ & $23.62 \pm 1.40^{\mathrm{a}, \mathrm{c}}$ & $<0.001^{\mathrm{d}}$ \\
\hline Lumenal area $\left(\mathrm{mm}^{2}\right)$ & $2.60 \pm 0.56$ & $4.62 \pm 0.27^{\mathrm{a}}$ & $4.04 \pm 0.44^{\mathrm{a}, \mathrm{b}}$ & $4.54 \pm 0.17^{\mathrm{a}, \mathrm{c}}$ & $<0.001^{\mathrm{d}}$ \\
\hline Neointimal area $\left(\mathrm{mm}^{2}\right)$ & $0.36 \pm 0.04$ & $0.12 \pm 0.02^{\mathrm{a}}$ & $0.15 \pm 0.03^{\mathrm{a}, \mathrm{b}}$ & $0.13 \pm 0.02^{\mathrm{a}}$ & $<0.001^{\mathrm{d}}$ \\
\hline Medial area $\left(\mathrm{mm}^{2}\right)$ & $0.53 \pm 0.04$ & $0.45 \pm 0.03^{\mathrm{a}}$ & $0.49 \pm 0.03^{\mathrm{a}}$ & $0.47 \pm 0.03^{\mathrm{a}}$ & $<0.001^{\mathrm{d}}$ \\
\hline Neointimal/medial & $0.67 \pm 0.06$ & $0.26 \pm 0.04^{\mathrm{a}}$ & $0.32 \pm 0.06^{\mathrm{a}, \mathrm{b}}$ & $0.27 \pm 0.03^{\mathrm{a}}$ & $<0.001^{\mathrm{d}}$ \\
\hline
\end{tabular}

Data are presented as the mean \pm standard deviation and tested by analysis of variance with Tukey's test or Dunnet's T3 test for post hoc analysis. Bold values indicate a statistically significant difference. ${ }^{\mathrm{a}} \mathrm{P}<0.05$ compared with the control group. ${ }^{\mathrm{b}} \mathrm{P}<0.05$ compared with the CsA group. ${ }^{\mathrm{P}} \mathrm{P}<0.05$ compared with the low-dose group. ${ }^{\mathrm{d}} \mathrm{P}<0.05$ between the 4 groups. VD, vessel diameter; POVD, post-operative vessel diameter.

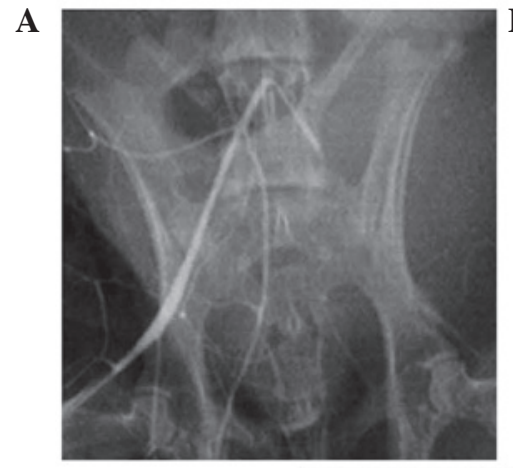

D

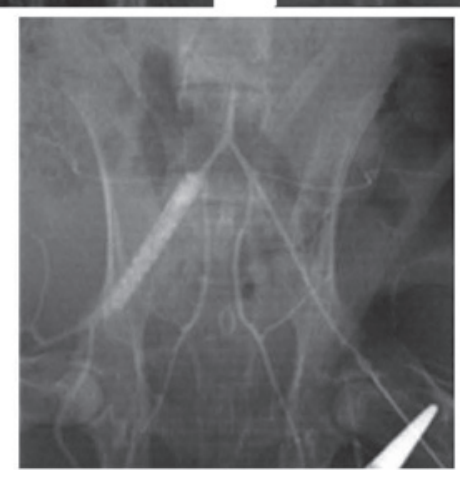

B

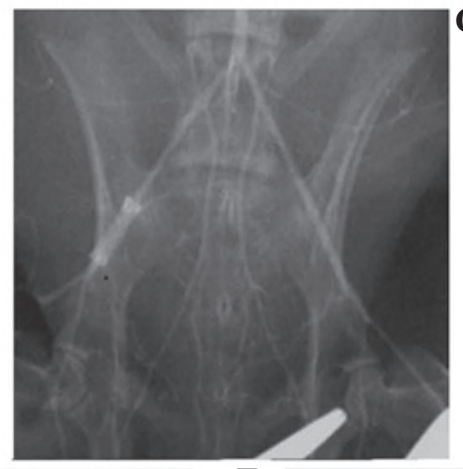

$\mathbf{E}$

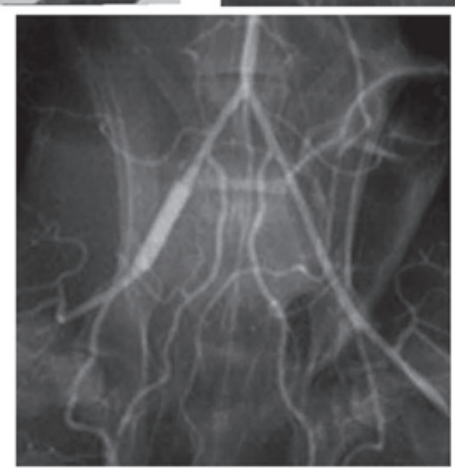

Figure 1. Angiography of iliac artery stenosis was conducted (A) prior to implantation or (B-E) 28 days later. (B) Control group, (C) cyclosporin A group, (D) low-dose and (E) high-dose tripterygium glycosides groups.

implantation is also demonstrated (Fig. 1A). The baseline VD, POVD, lumenal area, NI, M and ratio of NI-to-M of rabbits in the 4 groups are listed in Table I. The baseline VD and POVD were similar in all groups. However, 28 days after administration of therapeutic agents, the POVD values in all rabbits in the CsA and tripterygium glycosides groups were significantly increased compared with those of the control group. Although the POVD of the low-dose group was significantly smaller than that of the CsA group at 28 days, the high-dose and the CsA groups had comparable POVD. The greatest reductions and percentage changes in POVD were observed in the control group, and the lowest changes were observed in the CsA and high dose tripterygium glycosides groups. Thus, the high-dose of tripterygium glycosides exerted a similar effect on POVD at day 28, when POVD loss and percentage change of the POVD was compared with CsA. Excluding the lumenal area, the NI, M and the ratio of NI-to-M in the CsA and tripterygium glycosides groups were significantly smaller than those of the control group. The lumenal area in the control group was significantly smaller than that in the other groups. Although 
Table II. Post-operative protein expression of PCNA, VEGF, CDK2 and p21 Cip1 (optical density) in 24 rabbits.

\begin{tabular}{lcccc}
\hline Protein & $\begin{array}{c}\text { Vehicle control } \\
(\mathrm{n}=6)\end{array}$ & $\begin{array}{c}\text { CsA } \\
(\mathrm{n}=6)\end{array}$ & $\begin{array}{c}\text { Low-dose tripterygium } \\
\text { glycosides }(\mathrm{n}=6)\end{array}$ & $\begin{array}{c}\text { High-dose tripterygium } \\
\text { glycosides }(\mathrm{n}=6)\end{array}$ \\
\hline PCNA & $0.091 \pm 0.007$ & $0.032 \pm 0.005^{\mathrm{a}}$ & $0.057 \pm 0.009^{\mathrm{a}, \mathrm{b}}$ & $0.031 \pm 0.010^{\mathrm{a}, \mathrm{c}}$ \\
VEGF & $0.044 \pm 0.005$ & $0.010 \pm 0.003^{\mathrm{a}}$ & $0.030 \pm 0.004^{\mathrm{a}, \mathrm{b}}$ & $0.010 \pm 0.002^{\mathrm{a}, \mathrm{c}}$ \\
CDK2 & $0.069 \pm 0.003$ & $0.032 \pm 0.001^{\mathrm{a}}$ & $0.041 \pm 0.002^{\mathrm{a}, \mathrm{b}}$ & $0.030 \pm 0.001^{\mathrm{a}, \mathrm{c}}$ \\
p21 & $0.020 \pm 0.004$ & $0.087 \pm 0.005^{\mathrm{a}}$ & $0.049 \pm 0.005^{\mathrm{a}, \mathrm{b}}$ & $0.082 \pm 0.010^{\mathrm{a}, \mathrm{c}}$ \\
\hline
\end{tabular}

Data are presented as the mean \pm standard deviation and tested by analysis of variance with Tukey's test or Dunnet's T3 test for post hoc analysis. Bold values indicate a statistically significant difference. ${ }^{\mathrm{a}} \mathrm{P}<0.05$ compared with the control group. ${ }^{\text {b }} \mathrm{P}<0.05$ compared with the $\mathrm{Cs} A$ group. ${ }^{\mathrm{C}} \mathrm{P}<0.05$ compared with the low-dose group. ${ }^{\mathrm{d}} \mathrm{P}<0.05$ between the 4 groups. PCNA, proliferating cell nuclear antigen; VEGF, vascular endothelial growth factor; CDK2, cyclin-dependent kinase 2; p2 ${ }^{\text {Cipl }}$, cyclin-dependent kinase 1.

A

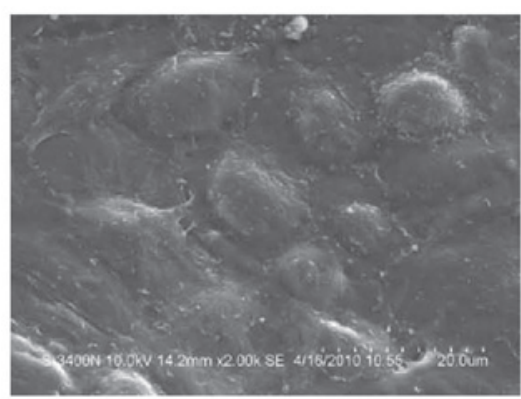

C

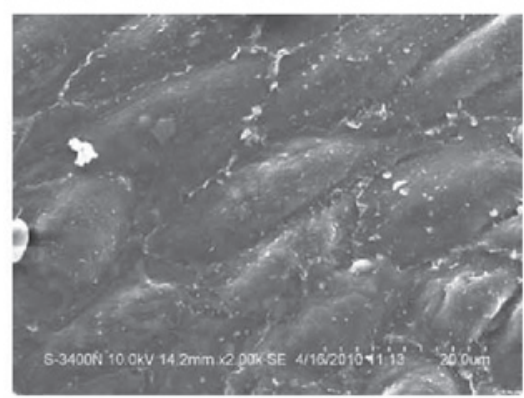

B

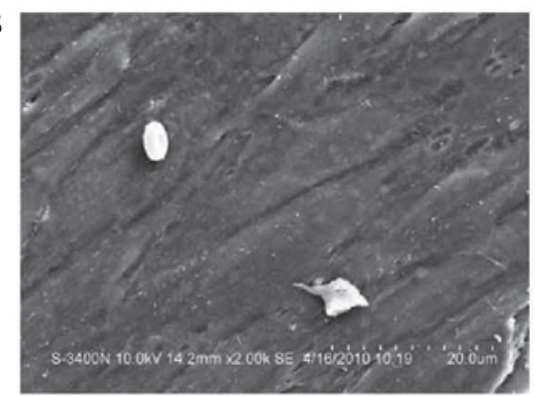

D

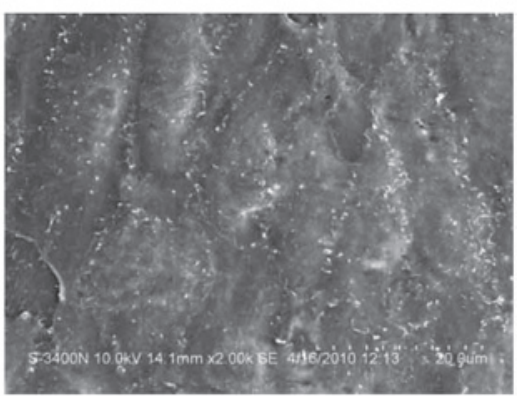

Figure 2. Scanning electron microscope observation of the rabbit iliac artery was conducted 28 days after administration of the therapeutic agents (magnification, $\mathrm{x} 2000$ ). (A) Control group demonstrating disordered alignment of endothelial cells, (B) CsA group demonstrating relatively regular alignment close to the direction of blood flow, (C) low-dose and (D) high-dose tripterygium glycosides groups demonstrating similar cell alignment to the CsA group with increased microvilli. CsA, cyclosporin A.

smaller lumenal area and greater NI area, as well as the ratio of NI-to-M were observed in the low-dose tripterygium glycosides group when compared with the CsA, the CsA group and the high-dose group had comparable values of these variables. The lowest ratio of NI-to-M was observed in the CsA group, and the largest ratio was observed in the control group.

Cells treated with high-dose tripterygium glycosides exhibit almost normal endothelial cell alignment. Scanning electron microscopy observation of the rabbit iliac artery, which was conducted 28 days after administration of therapeutic agents, is presented in Fig. 2. In the bare stent control group, the alignment of endothelial cells on the intimal surface of new blood vessels was relatively disordered, the sizes and morphologies of cells were different, the nuclei were irregular, and the intercellular space was relatively large. In the low-dose tripterygium glycosides group, the alignment of endothelial cells on the intimal surface was relatively regular compared with the bare stent control group, and the size, morphology, nuclear morphology and intercellular space were markedly improved than those of the bare stent group. In the CsA group, the alignment of endothelial cells on the intimal surface of new blood vessels was relatively regular and tight, the direction of alignment was close to the direction of blood flow, the intercellular space was relatively small, the morphology and size of endothelial cells were relatively identical, and the nuclei were relatively regular. The intercellular space and endothelial cells were almost normal. Numerous scattered microvilli were observed on cell surfaces. In the high-dose tripterygium glycosides group, the alignment of endothelial cells on the intimal surface of new blood vessels, the size, morphology, nuclear morphology and intercellular space were similar to those in the CsA group. However, the microvilli were distributed along the outline of cells and the distribution was more even with increased number, which suggests that the function of these cells was closer to that of the normal endothelial cells. 

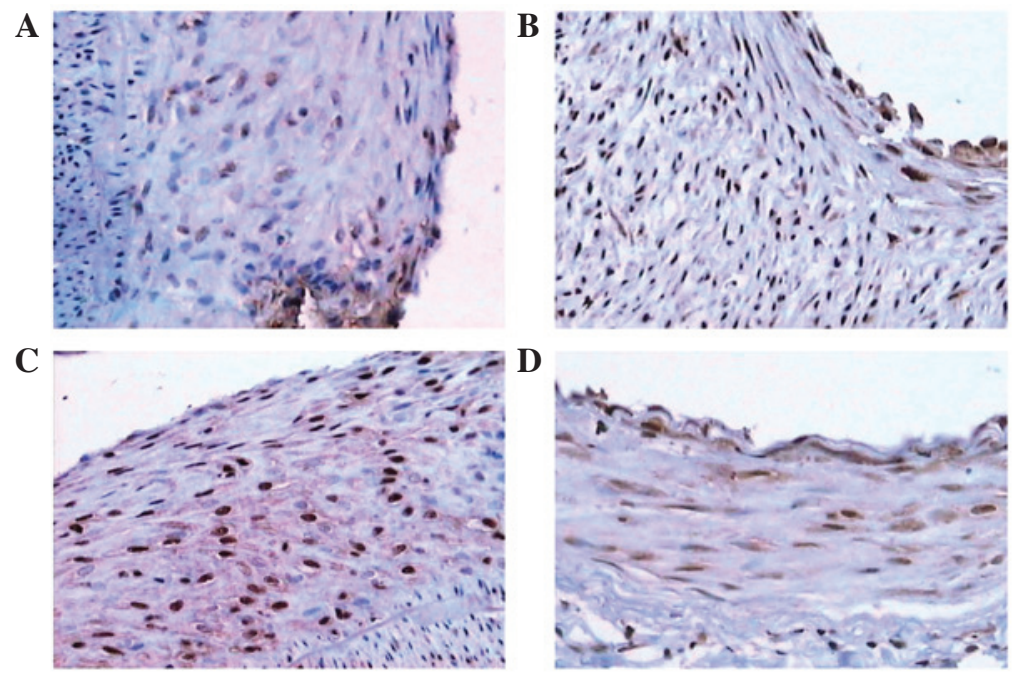

Figure 3. Rabbit iliac arteries. The representative immunohistochemistry images of proliferating cell nuclear antigen (magnification, x200). (A) Control group, (B) cyclosporin A group, and (C) low-dose and (D) high-dose tripterygium glycosides groups.
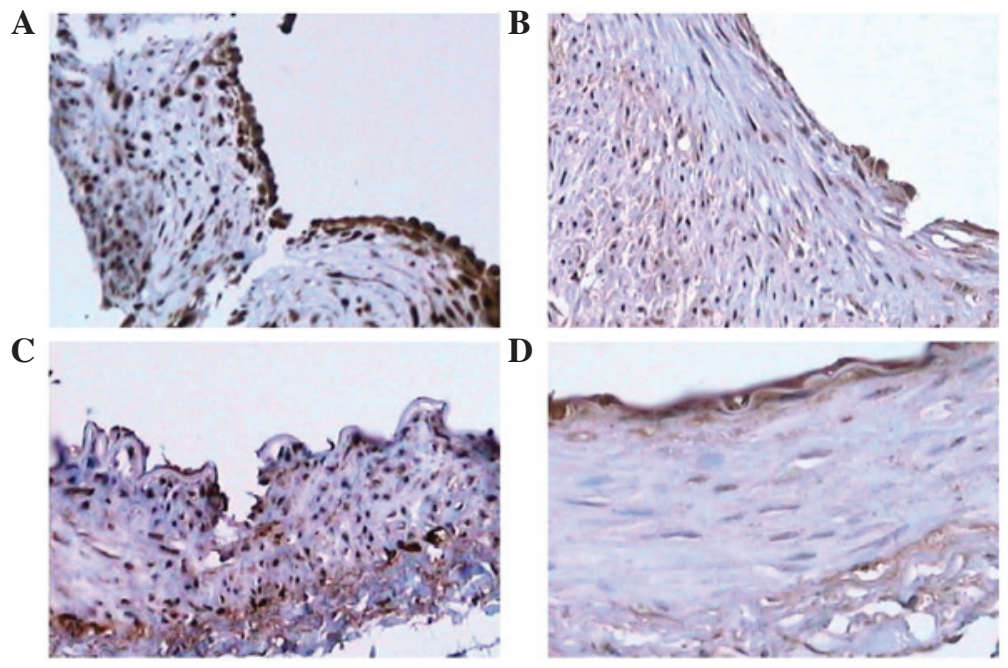

Figure 4. Rabbit iliac arteries. The representative immunohistochemistry images of vascular endothelial growth factor (magnification, x200). (A) Control group, (B) cyclosporin A group, and (C) low-dose and (D) high-dose tripterygium glycosides groups.

Tripterygium glycosides downregulate the expression of $P C N A, V E F G$ and $C D K 2$ and upregulated expression of $p 21^{\text {Cipl }}$. Protein expression of PCNA, VEFG, CDK2 and p21 $1^{\text {Cipl }}$ are listed in Table II. Compared with rabbits in the vehicle control group, CsA and tripterygium glycosides at high and low doses significantly downregulated protein expression of PCNA, VEFG and CDK2, however, they significantly upregulated $\mathrm{p} 21^{\mathrm{Cip} 1}$ protein expression (all $\mathrm{P}<0.001$ ). Notably, the high-dose group and CsA group had comparable levels of all four proteins. The representative IHC images are presented in Figs 3-6.

Administration of tripterygium glycosides results in adverse reactions in five patients. Five patients in the treatment group had adverse reactions that were resolved following therapeutic agent withdrawal, they were excluded from the final analysis of the present study. In the low-dose tripterygium group, one patient had nausea and vomiting, and another had an abnormal blood cell response (leukopenia, erythroblastopenia and granulocytopenia). In the high-dose group, one patient had nausea and vomiting, one had an abnormal blood cell response (leukopenia, erythroblastopenia and granulocytopenia), and a third patient had low blood pressure and an accelerated heart rate.

No significant difference is observed in baseline characteristics of the patients. Baseline characteristics of all patients are presented in Table III. Among the three groups of patients, there were no significant differences in age, gender distribution, course of disease, and prevalence of hypertension, cardiovascular disease, cerebrovascular disease, intermittent claudication, hyperlipidemia, leg pain, leg ulcer, leg coldness, and Trans-Atlantic Inter-Society Consensus (TASC) stage.

IL-10 and IL-18 are significantly reduced following treatment with tripterygium glycosides. The three groups of patients had comparable levels of IL-10, IL-18, CRP and intima-media thickness when measured at the baseline (Table IV). 

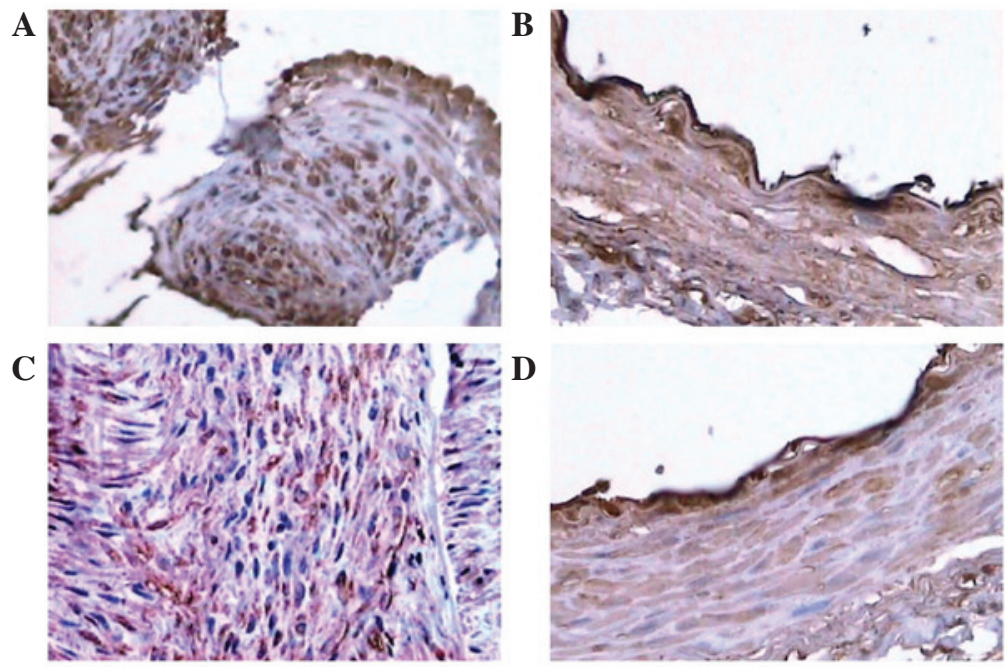

Figure 5. Rabbit iliac arteries. The representative immunohistochemistry images of cyclin-dependent kinase 2 (magnification, x200). (A) Control group, (B) cyclosporin A group, and (C) low-dose and (D) high-dose tripterygium glycosides groups.

A

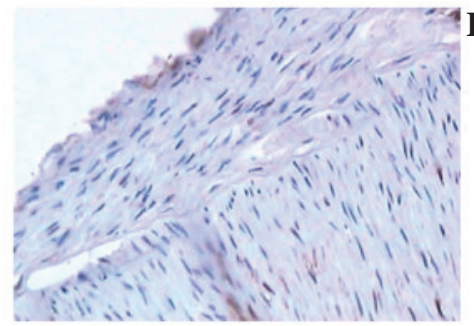

C

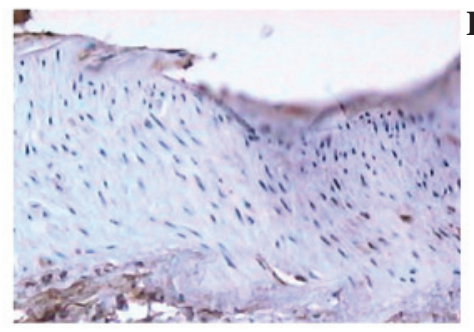

B

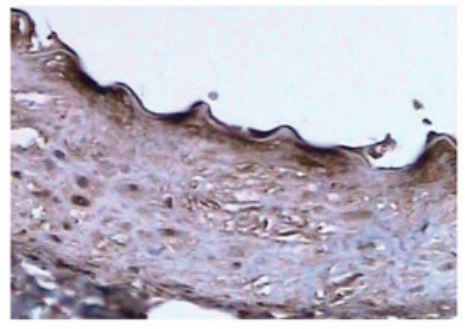

D

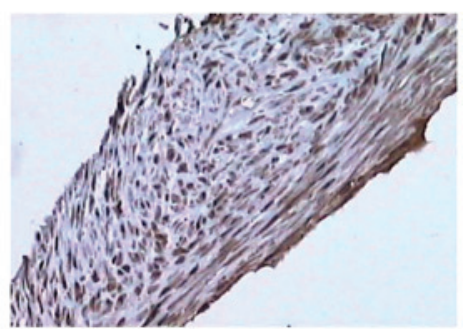

Figure 6. Rabbit iliac arteries. The representative immunohistochemistry images of cyclin-dependent kinase 1 (magnification, x200). (A) Control group, (B) cyclosporin A group, and (C) low-dose and (D) high-dose tripterygium glycosides groups.

One month after the surgery, IL-10 and IL-18 levels were increased, and then decreased in the 2nd month in all groups. Tripterygium glycosides at the two doses significantly reduced IL-10 and IL-18 levels compared with those in the control group. Although the CRP level and intima-media thickness of the control group were slightly elevated following surgery, no significant differences were observed in these parameters among the three patient groups.

Six months following the surgery, the stent patency rate in patients with bare stents was lower compared with that in patients receiving tripterygium glycosides. At 6 months, the stent patency rates were $67.5 \%$ in the control group, $90.9 \%$ in the low-dose group and $93.8 \%$ in the high-dose group $(\mathrm{P}=0.004)$; at 12 months, the rates for each group were $62.5 \%$ for the control group, $84.8 \%$ for the low-dose group and $90.6 \%$ for the high-dose group $(\mathrm{P}=0.009)$. Patients administered tripterygium glycosides had higher ankle-brachial index than those not administered tripterygium glycosides, 0.47 vs.
0.73 in the low-dose group and 0.79 in the high-dose group at 6 months; 0.49 vs. 0.70 in the low-dose group and 0.75 in the high-dose group at 12 months $(\mathrm{P}<0.001$ for the two doses; Table V).

\section{Discussion}

Results of the present experimental study demonstrated that CsA and tripterygium glycosides inhibited DNA synthesis in cellular proliferation, inhibited regulation of chromosomal DNA replication in $\mathrm{S}$ phase, suppressed aggravation of immune rejection and enhancement of inflammatory cell infiltration, and decreased cell cycle progression, inducing G1, G2 and S-phase arrest. In addition, the alignment of endothelial cells on the intimal surface in the tripterygium glycosides low and high dose groups was more regular than that in the bare stent group, and the size, morphology, nuclear morphology and cell patency were markedly improved in the tripterygium glycosides groups compared with those in the bare stent 
Table III. Baseline characteristics in 120 patients by group.

\begin{tabular}{|c|c|c|c|c|}
\hline Characteristic & $\begin{array}{l}\text { Control } \\
(\mathrm{n}=40)\end{array}$ & $\begin{array}{l}\text { Low-dose tripterygium } \\
\text { glycosides }(\mathrm{n}=40)\end{array}$ & $\begin{array}{l}\text { High-dose tripterygium } \\
\text { glycosides }(\mathrm{n}=40)\end{array}$ & P-value \\
\hline Age (years) & $64.8 \pm 15.8$ & $65.1 \pm 16.6$ & $63.9 \pm 17.2$ & 0.945 \\
\hline Male gender, n (\%) & $29(72.5)$ & $31(77.5)$ & $30(75.0)$ & 0.964 \\
\hline Course (months) & $4.9 \pm 2.9$ & $4.8 \pm 3.2$ & $4.9 \pm 3.1$ & 0.986 \\
\hline Hypertension, n (\%) & $28(70.0)$ & $29(72.5)$ & $30(75.0)$ & 0.966 \\
\hline $\mathrm{CAD}, \mathrm{n}(\%)$ & $20(50.0)$ & $19(47.5)$ & $21(52.5)$ & 0.973 \\
\hline CVD, n (\%) & $10(25.0)$ & $9(22.5)$ & $11(27.5)$ & 0.964 \\
\hline Diabetes, n (\%) & $9(22.5)$ & $10(25.0)$ & $10(25.0)$ & 0.999 \\
\hline Hyperlipidemia, n (\%) & $28(70.0)$ & $27(67.5)$ & $29(72.5)$ & 0.968 \\
\hline IMC, $\mathrm{n}(\%)$ & $24(60.0)$ & $25(62.5)$ & $26(65.0)$ & 0.971 \\
\hline Leg pain, n (\%) & $18(45.0)$ & $16(40.0)$ & $19(47.5)$ & 0.848 \\
\hline Leg ulcer, n (\%) & $7(17.5)$ & $9(22.5)$ & $8(20.0)$ & 0.958 \\
\hline Leg coldness, n (\%) & $29(72.5)$ & $30(75.0)$ & $31(77.5)$ & 0.999 \\
\hline TASC stage, n (\%) & & & & 0.945 \\
\hline A & $19(47.5)$ & $18(45.0)$ & $20(50.0)$ & \\
\hline B & $18(45.0)$ & $17(42.5)$ & $17(42.5)$ & \\
\hline $\mathrm{C}$ & $3(7.5)$ & $5(12.5)$ & $3(7.5)$ & \\
\hline
\end{tabular}

Age is presented as the mean \pm standard deviation and other values are expressed as $\mathrm{n}(\%)$. Analysis of variance followed by Tukey's test for post hoc tests and $\chi^{2}$ were implemented. CAD, cardiovascular disease; CVD, cerebro-vascular disease; IMC, intermittent claudication; TASC, Trans-Atlantic Inter-Society Consensus.

control group. The present study hypothesized that CsA and tripterygium glycosides may inhibit and delay the occurrence of ISR. Results of the present study demonstrated that tripterygium glycosides inhibited the expression of PCNA, CDK2 and VEGF proteins and enhanced $\mathrm{p} 21^{\mathrm{Cipl}}$ protein expression in VSMCs. These effects on important cell-cycle proteins were more marked in the high-dose tripterygium glycosides group, suggesting that the administration of tripterygium glycosides inhibited ISR formation. Results of the present experimental study also indicated that immune rejection was involved in ISR formation, which may be an important mechanism provoking ISR.

Results from the clinical observation of 120 patients in the current study demonstrated that the patency rate of the diseased blood vessels was reduced to $60 \%$ at 12 months following endovascular treatment in the control group, while the patency rate was $85 \%$ in the tripterygium glycosides group. In addition, the therapeutic outcomes of high-dose tripterygium glycosides administration were improved compared with those of the low-dose tripterygium glycosides. Plasma IL-10 and IL-18 levels in the tripterygium glycosides group were significantly lower than those in the control group, indicating notable anti-inflammatory effects. The safety of administration of tripterygium glycosides was indicated by the limited number of mild adverse reactions ( 5 patients with digestive, blood cell or cardiologic disturbances), which resolved following therapeutic agent withdrawal.

Restenosis or occlusion following endovascular treatment is a critical clinical problem for vascular surgeons, and intimal hyperplasia is a characteristic pathological feature of the restenosis following endovascular treatment (20).
Hyperproliferation of VSMCs and their migration to the intima within the diseased blood vessels are important pathological bases of neointimal hyperplasia and the key pathological features of numerous factors inducing restenosis following recanalization (21). Currently, the use of drug-eluting stents is reducing restenosis. Tao et al (16) coated stents with a mixture of synthetic polymers blended with triptolide and demonstrated that the triptolide-eluting stents inhibited neointimal formation in a rabbit iliac artery model. As in the current study, the inhibition of VSCM proliferation by extracts of TWHF (triptolide and tripterygium glycosides) is an important indicator of the regulatory mechanism underlying vascular wall tension, which is crucial in preventing restenosis. Another similarity between the results of the present study and those of Tao et al (16) is the upregulation of $\mathrm{p}^{2} 1^{\mathrm{Cip} 1}$, suggesting that the antiproliferative effect of TWHF extracts on VSCM may be associated with $\mathrm{p} 21^{\mathrm{Cip} 1}$ expression.

Statins have also been employed to inhibit neointima hyperplasia and vascular inflammation. However, a recent comparison of an atorvastatin-eluting stent vs. a paclitaxel-eluting stent in a rabbit iliac artery overstretch restenosis model did not demonstrate significant differences in neointimal hyperplasia, but did demonstrate more effective arterial healing within arteries of rabbits receiving atorvastatin (22). In another study comparing long-term clinical and angiographic outcomes of patients with severe calcified lesions following administration of one of two widely used drug-eluting stents, the paclitaxel-eluting stent or the sirolimus-eluting stent, no significant differences were demonstrated between the two therapeutic agents (restenosis rates were $21.1 \%$ for sirolimus and $17.5 \%$ for paclitaxel) (23). Direct drug-eluting stenting 
Table IV. IL-10, IL-18, CRP and IMT of lower limbs in 120 patients.

\begin{tabular}{|c|c|c|c|c|}
\hline Parameter & $\begin{array}{l}\text { Control } \\
(\mathrm{n}=40)\end{array}$ & $\begin{array}{l}\text { Low-dose tripterygium } \\
\text { glycosides }(n=36)\end{array}$ & $\begin{array}{l}\text { High-dose tripterygium } \\
\text { glycosides }(n=32)\end{array}$ & P-value \\
\hline IL-10 (pg/ml) & & & & $<0.001^{\mathrm{a}}$ \\
\hline Baseline & $20.03 \pm 7.68$ & $20.87 \pm 8.12$ & $20.55 \pm 7.67$ & 0.889 \\
\hline 1 month & $33.64 \pm 9.65^{\mathrm{b}}$ & $24.21 \pm 7.04^{\mathrm{b}, \mathrm{c}}$ & $22.58 \pm 5.99^{\mathrm{b}, \mathrm{c}}$ & $<0.001^{\mathrm{a}}$ \\
\hline 2 months & $30.28 \pm 8.68^{\mathrm{d}, \mathrm{e}}$ & $22.38 \pm 6.45^{\mathrm{b}-\mathrm{d}}$ & $21.24 \pm 5.90^{\mathrm{c}, \mathrm{d}}$ & $<0.001^{\mathrm{a}}$ \\
\hline $\mathrm{P}_{\text {time group }}{ }^{*}$ & $<0.001$ & & & \\
\hline IL-18 (pg/ml) & & & & $<0.001^{\mathrm{a}}$ \\
\hline Baseline & $42.70 \pm 11.67$ & $41.91 \pm 11.85$ & $41.79 \pm 11.97$ & 0.932 \\
\hline 1 month & $68.97 \pm 15.13^{\mathrm{b}}$ & $46.71 \pm 13.21^{\mathrm{b}, \mathrm{c}}$ & $42.94 \pm 12.06^{\mathrm{c}}$ & $<0.001^{\mathrm{a}}$ \\
\hline 2 months & $55.64 \pm 13.41^{\mathrm{d}, \mathrm{e}}$ & $42.70 \pm 12.62^{c}$ & $41.14 \pm 11.75^{\mathrm{c}, \mathrm{d}}$ & $<0.001^{\mathrm{a}}$ \\
\hline $\mathrm{P}_{\text {time group }}{ }^{\mathrm{e}}$ & $<0.001$ & & & \\
\hline CRP & & & & 0.311 \\
\hline Baseline & $1.08 \pm 0.22$ & $1.09 \pm 0.22$ & $1.11 \pm 0.24$ & \\
\hline 1 month & $1.19 \pm 0.18^{b}$ & $1.09 \pm 0.19$ & $1.08 \pm 0.15$ & \\
\hline 2 months & $1.19 \pm 0.23^{\mathrm{b}}$ & $1.08 \pm 0.15$ & $1.12 \pm 0.23$ & \\
\hline $\mathrm{P}_{\text {time group }}{ }^{\mathrm{e}}$ & $<0.001$ & & & \\
\hline IMT of lower limb (mm) & & & & 0.277 \\
\hline Baseline & $1.08 \pm 0.22$ & $1.09 \pm 0.22$ & $1.11 \pm 0.24$ & \\
\hline 1 month & $1.19 \pm 0.18^{b}$ & $1.09 \pm 0.19$ & $1.08 \pm 0.15$ & \\
\hline 2 months & $1.19 \pm 0.23^{b}$ & $1.08 \pm 0.15$ & $1.09 \pm 0.22$ & \\
\hline $\mathrm{P}_{\text {time group }}{ }^{\mathrm{e}}$ & $<0.001$ & & & \\
\hline
\end{tabular}

Data are presented as the mean \pm standard deviation and tested by generalized estimation equation, Bonfferoni's correction test was applied for multiple comparisons. Bold values indicate statistically significant results. ${ }^{a} \mathrm{P}<0.05$ between the three groups. ${ }^{\mathrm{b}} \mathrm{P}<0.05$, compared with baseline. ${ }^{\mathrm{c}} \mathrm{P}<0.05$ compared with the control group. ${ }^{\mathrm{d}} \mathrm{P}<0.05$ compared with the previous 1 month. ${ }^{\mathrm{e}} \mathrm{P}$ value of an interaction term consisting of time and group. Once a significant result of the interaction term is revealed $\left(\mathrm{P}_{\text {time }}{ }^{*}\right.$ group $\left.{ }^{\mathrm{g}}<0.05\right)$, the time effect on a given variable should be separately tested by group. IL, interleukin; CRP, C-reactive reactive protein; IMT, intima-media thickness.

Table V. Stent patency rates and ABI in 120 patients.

\begin{tabular}{lccc}
\hline Parameter & $\begin{array}{c}\text { Vehicle control } \\
(\mathrm{n}=40)\end{array}$ & $\begin{array}{c}\text { Low-dose tripterygium } \\
\text { glycosides }(\mathrm{n}=33)\end{array}$ & $\begin{array}{c}\text { High-dose tripterygium } \\
\text { glycosides }(\mathrm{n}=32)\end{array}$ \\
\hline $\begin{array}{l}\text { Number of unobstructed } \\
\text { stents }(\%)\end{array}$ & & & \\
6 Months & $27(67.5)$ & $30(90.9)^{\mathrm{a}}$ & $30(93.8)^{\mathrm{a}}$ \\
12 Months & $25(62.5)$ & $28(84.8)^{\mathrm{a}}$ & $29(90.6)^{\mathrm{a}}$ \\
ABI & $0.47 \pm 0.23$ & $0.73 \pm 0.17^{\mathrm{a}}$ & $0.79 \pm 0.16^{\mathrm{a}}$ \\
6 Months & $0.49 \pm 0.18$ & $0.70 \pm 0.22^{\mathrm{a}}$ & $0.75 \pm 0.19^{\mathrm{a}}$ \\
\hline
\end{tabular}

Number of stents without obstruction is presented as count $(\%)$ and tested by $\chi^{2}$ test. ABI is shown as the mean \pm standard deviation and tested by analysis of variance, followed by post hoc testing using Tukey's test. Bold values indicate a statistically significant difference. ${ }^{a} \mathrm{P}<0.05$, compared with the control group. ${ }^{\mathrm{b}} \mathrm{P}<0.05$ between the 3 groups. $\mathrm{ABI}$, ankle-brachial index.

without pre-dilation also did not reduce restenosis compared with conventional or provisional stenting in patients with percutaneous coronary intervention (24).

Tripterygium glycosides were previously reported to exert strong anti-inflammatory and immunosuppressive effects (10). Tripterygium glycosides tablets have been demonstrated to reduce the inflammatory response in rat lung tissue (25), and the mechanism in the rat model of arthritis was hypothesized to be associated with upregulating IL-10 expression and downregulating tumor necrosis factor (TNF)- $\alpha$ levels (26). The anti-inflammatory properties include antagonizing and inhibiting the release of inflammatory mediators and 
the degree of response. The immunosuppressive properties include inhibition of T-cell function, delayed-type hypersensitivity, IL-1 secretion and antigen-stimulated cell division and reproduction. Results from the present study have indicated the involvement of immune rejection as a factor in ISR formation, this suggests that the immunosuppressive effects of tripterygium glycosides may effectively inhibit ISR.

Limitations of the present study include that serum cytokines in rabbits were not quantified in the experimental study. In addition, although IL-10 and IL-18 were quantified in patients in the clinical study, the typical pro- and anti-inflammatory cytokines, including IL- $1 \beta$, IL- 6 , IL-4 and TNF- $\alpha$, were not measured. The patients' vessel diameter and percent stenosis were also not measured in the clinical trial, which may improve the analysis of future results. These measures remain to be completed in future investigation. Further investigation into the antiproliferative effects of tripterygium glycosides is particularly required to confirm and expand the results of the present study, and to continue to investigate the inhibition of ISR formation and associated mechanisms. Long-term follow up of clinical outcomes is also required.

In conclusion, results of the present experimental and clinical studies have demonstrated that the anti-inflammatory and immunosuppressive effects of tripterygium glycosides may inhibit in-stent restenosis formation following endovascular treatment of lower-extremity artery disease. Thus, tripterygium glycosides may be a candidate for preventing stent restenosis and/or reducing restenosis rates currently observed in clinical practice.

\section{References}

1. Xu N, Zhang J, Li M, Pan J and Lu Z: Incidence and classification of neointimal proliferation and in-stent restenosis in post-stenting patients at 1-year interval: Findings from non-invasive coronary computed tomography angiography. Eur J Radiol 83: 1816-1821, 2014.

2. Schillinger M, Sabeti S, Loewe C, Dick P, Amighi J, Miekusch W, Schlager O, Cejna M, Lammer J and Minar E: Balloon angioplasty versus implantation of nitinol stents in the superficial femoral artery. N Engl J Med 354: 1879-1888, 2006.

3. Kipshidze N, Leon MB, Tsapenko M, Falotico R, Kopia GA and Moses J: Update on sirolimus drug-eluting stents. Curr Pharm Des 10: 337-348, 2004.

4. Schmieder GC, Richardson AI, Scott EC, Stokes GK, Meier GH 3rd and Panneton JM: Selective stenting in subintimal angioplasty: Analysis of primary stent outcomes. J Vasc Surg 8: 1175-1180, 2008

5. Han B, Wang J, Wang B and Wang Z: Clinical analysis of endovascular treatment of patients with diabetic arteriosclerosis obliteration of lower extremity. Chinese Journal of General Surgery 24: 243-244, 2009 (In Chinese).

6. Han B, Wang J, Wang B and Wang Z: Treatment of arteriosclerosis obliterans of lower extremity associated with thrombus formation. Clinical Medicine of China 26: 207-208, 2010 (In Chinese).

7. Li YJ, Guan Yan and Wang ZL: Gene therapy restenosis. Chinese Journal of Arteriosclerosis 9: 77-81, 2001 (In Chinese).

8. Maisel WH and Laskey WK: Cardiology patient page. Drug-eluting stents. Circulation 115: e426-e427, 2007.
9. Stettler C, Wandel S, Allemann S, Kastrati A, Morice MC, Schömig A, Pfisterer ME, Stone GW, Leon MB, de Lezo JS, et al: Outcomes associated with drug-eluting and bare-metal stents: A collaborative network meta-analysis. Lancet 370: 937-948, 2007.

10. Gu WZ, Chen R, Brandwein S, McAlpine J and Burres N: Isolation, purification and characterization of immunosuppressive compounds from tripterygium: Triptolide and tripdiolide. Int J Immunopharmacol 17: 351-356, 1995.

11. Tao X and Lipsky PE: The Chinese anti-inflammatory and immunosuppressive herbal remedy Tripterygium wilfordii Hook F. Rheum Dis Clin North Am 26: 29-50, 2000.

12. Chen BJ: Triptolide, a novel immunosuppressive and anti-inflammatory agent purified from a Chinese herb, Tripterygium wilfordii Hook F. Leuk Lymphoma 42: 253-265, 2001.

13. Dai C, Wang P, Zhang X and Zhu L: Triptolide PG490-88 combined with cyclosporin $\mathrm{A}$ induces immune tolerance in a rat renal allograft rejection model. Chinese Journal of Tissue Engineering Research 15: 861-864, 2011 (In Chinese).

14. Lin J, Chen L, Lin Z and Zhao M: Inhibitory effect of triptolide on multiforme in vitro. J Int Med Res 35: 490-496, 2007.

15. Chang WT, Kang JJ, Lee KY, Wei K, Anderson E, Gotmare S, Ross JA and Rosen GD: Triptolide and chemotherapy cooperate in tumor cell apoptosis. A role for the p53 pathway. J Biol Chem 276: 2221-2227, 2001.

16. Tao R, Lu L, Zhang R, Hu J, Ni J and Shen W: Triptolide inhibits rat vascular smooth muscle cell proliferation and cell cycle progression via attenuation of ERK1/2 and Rb phosphoylation. Exp Mol Pathol 90: 137-142, 2011.

17. Fang W, Peng F, Yi T, Zhang C, Wan C, Lam CW and Yang X: Biological actity and safety of Tripterygium extract prepared by sodium carbonate extraction. Molecules 17: 11113-11123, 2012.

18. Zheng GH, Liu JP, Wang NS, Chen HY and Chu JF: Systematic review of Chinese herbal medicines for preventing in-stent coronary restenosis after percutaneous coronary intervention. Evid Based Complement Alternat Med 2012: 253409, 2012.

19. Shang D, Wang J and Bogen Z: Combination of Traditional Chinese and Western Medicing and Peripheral Vascular Diseases. People's Medical Publishing House Co., Ltd., Beijing, pp78-271, 2004.

20. Monahan TS, Andersen ND, Panossian H, Kalish JA, Daniel S, Shrikhande GV, Ferran C and Logerfo FW: A novel function for cadherin 11/osteoblast-cadherin in vascular smooth muscle cells: Modulation of cell migration and proliferation. J Vasc Surg 45: 581-589, 2007.

21. Liu Z and Li C: Effect of intravascular stent surface modification on tunica intimal hyperplasia. Chinese Journal of Tissue Engineering Research 14: 4721-4724, 2010 (In Chinese).

22. Lim KS, Jeong MH, Bac IH, Park JK, Park DS, Kim JM, Kim JH, Cho DL, Sim DS, Park KH, et al: Effect of atorvastatin-eluting stents in a rabbit iliac artery restenosis model. Chonnam Med J 49: 118-124, 2013.

23. Tsutsumi J, Ishikawa T, Nakano Y, Yoshimura M and Mutoh M: Long-term clinical and angiographic outcomes after sirolimusand paclitaxel-eluting stent placement following rotablation for severely calcified lesions: A retrospective nonrandomized study. Cardiovasc Interv Ther 30:29-37, 2015.

24. Remkes WS, Somi S, Roolvink V, Rasoul S, Ottervanger JP, Gosselink AT, Hoorntje JC, Dambrink JH, de Boer MJ, Suryapranata $\mathrm{H}$, et al: Direct drug-eluting stenting to reduce stent restenosis: A randomized comparison of direct stent implantation to conventional stenting with pre-dilation or provisional stenting in elective PCI patients. JACC Cardiovasc Interven 7: 751-758, 2014.

25. Wan L, Liu J, Huang CB, Wang Y, Lei L, Liu L, Cheng YY and Feng YX: Effect of tripterygium glycosides on pulmonary function in adjuvant arthritis rats. J Chin Med Assoc 76: 715-723, 2013 (In Chinese).

26. Wan L and Liu J: Changes of CD4(+) CD25(+) regulatory T cells, FoxP3 in adjuvant arthritis rats with damage of pulmonary function and effects of tripterygium glycosides tablets. Int J Rheumatol 2012: 348450, 2012. 